\title{
SUPPLEMENT TO THE
}

\section{BRITISH MEDICAL JOURNAL \\ LONDON SATURDAY MAY 251940}

\section{CONTENTS}

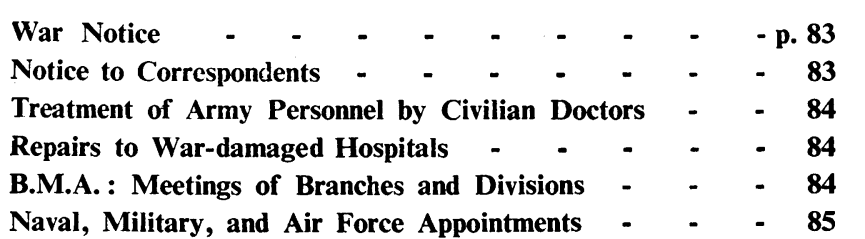

\section{WAR NOTICE}

Young Practitioners

The Central Medical War Committee has decided to deal centrally with the recruitment of $R$ practitioners holding house appointments in voluntary and municipal hospitals -other than those in the senior establishments of such hospitals.

Steps have been taken to obtain from all voluntary and municipal hospitals in England and Wales statements of their peacetime establishments and their estimated wartime establishments in terms of house officers. The following definitions are employed:

1. An $R$ practitioner is a practitioner who has registered under the National Service (Armed Forces) Act, 1939.

2. A posts are those whole-time resident house appointments at voluntary and municipal hospitals which are or can be occupied by practitioners without previous experience.

3. B posts are those whole-time posts, usually but not always resident, which cannot be occupied by practitioners without previous experience-that is, senior house-surgeons and physicians, casualty officers, resident surgical and medical officers, registrars and other officers intermediate between the junior house officer and the member of the visiting staff, or, in the case of the municipal hospital, intermediate between the junior house officer, if any; and the medical superintendent.

4. Some $B$ posts are part of the hospital senior establishment. At voluntary hospitals such senior posts are typically those of resident surgical officer, resident medical officer, registrar, chief assistant.

At the municipal hospital the senior establishment is comprised of those B appointments with a tenure of more than one year, and carrying with them a salary of $£ 350$ a year with emoluments, or more. These senior $\mathrm{B}$ posts are called $\mathrm{Bi}$ posts.
Correspondence :

Conscription of the Medical Profession. W. Wilson, M.D. p. 84

Postgraduate News and Diary - $\quad-\quad-\quad-\quad-\quad-\quad-86$

Diary of Societies and Lectures - $\quad-\quad-\quad-\quad-\quad-\quad-86$

Vacancies and Appointments - - - - - - $\quad$ - 86

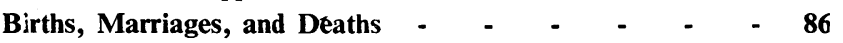

The hospitals of the country have been asked to state their establishments in terms of $A$ posts and $B$ posis; these establishments are being passed to Local Medical War Committees or, in the case of London, to the Committee of Reference for consideration. All holders of $A$ and $B$ posts, except those $B$ posts which are within the senior establishment-the Bi posts-will be dealt with by the Central Medical War Committee. The holders of $\mathrm{Bi}$ posts will be dealt with by the Local Medical War Committee or the Committee of Reference in the first instance.

In future, as a man qualifies he will fall to be dealt with centrally until he, not having been recruited by the Central Committee, undertakes work in a local area or obtains a post on the senior establishment of a voluntary or municipal hospital.

Central Medical War Committee,

B.M.A. House, Tavistock Square, W.C.1.

\section{NOTICE TO CORRESPONDENTS}

The need for strict economy in the use of paper for all purposes was emphasized by the Control of Paper Order made by the Ministry of Supply, which came into force last month. In view of the restrictions now imposed on the use of paper, and the increase in the rates of postage which came into operation on May 1, it will no longer be possible to acknowledge the receipt of letters and memoranda, etc., offered to the British Medical Journal for publication. The space devoted to correspondence has had to be curtailed, and readers are urged once again to be concise in all communications addressed to the Editor.

\section{RESOLUTIONS BY DIVISIONS AND BRANCHES FOR THE REPRESENTATIVE BODY Correction}

The Motion by Dover and Folkestone published in last week's Supplement at page 81 was printed in error. The motion was not adopted by the Division. 